\begin{abstract}
УДК 551.556.3:620.92(571.56)
ВЕТРОЭНЕРГОРЕСУРСЫ СЕВЕРНЫХ ТЕРРИТОРИЙ ЯКУТИИ

Ноговицын Д.Д., Шеина 3.М., Сергеева Л.П.

Институт физико-технических проблем Севера им. В.П. Ларионова СО РАН (ИФТПС СО РАН), Якутск, e-mail: dmitry-nogovitzyn@yandex.ru

Важнейшей составляющей развития ветроэнергетики является определение ее ресурсного потенциала. Характеристика ветрового ресурса на Крайнем Севере с её обширной территорией и суровой продолжительной зимой имеет огромное значение для всех аспектов использования энергии ветра, начиная от выбора подходящего места расположения ветроэлектростанций до определения подходящих для этих условий типов ветроэнергоустановок. На территории Якутии наибольшим ветроэнергетическим потенциалом для энергоснабжения обладают районы арктической зоны. В связи с этим подсчет запасов энергии ветра на арктической территории Якутии имеет практическое значение для районов, удаленных от источников централизованного энергоснабжения, и для относительно мелких потребителей энергии, рассредоточенных на обширных пространствах. В настоящее время в связи с повышением стоимости привозного жидкого и твердого топлива в отдаленные изолированные районы республики актуальным становится изыскание возможностей использования местных возобновляемых источников энергии, связанное с экономией топливно-энергетических ресурсов и решением экологических проблем. Основное внимание в статье уделено определению ветроэнергетического потенциала на территории Якутии. Необходимость уточнения запасов энергии ветра основана на прямой зависимости режима ветра от окружающей местности и от географического положения точки наблюдения. Анализ среднегодовых скоростей ветра метеостанций показал, что наиболее сильные ветра наблюдаются на побережье Северного Ледовитого океана (Анабарский, Булунский, Усть-Янский, Аллаиховский и Нижнеколымский районы) и нижнего течения р. Лены. Рассчитаны ветроэнергетические характеристики на всей территории Республики Саха (Якутия). Поскольку для выбранных районов энергия ветра является приоритетной, необходимы дополнительные научно-исследовательские работы по уточнению значений скоростей ветров, их повторяемости и направлению для точной оценки ветроэнергетического потенциала и обоснования размещения ветроэлектростанций.
\end{abstract}

Ключевые слова: Якутия, Арктика, ветроэнергоресурсы, скорость ветра, ветроэнергетический потенциал

\title{
WIND ENERGY RESOURCES OF THE NORTHERN TERRITORIES OF YAKUTIA
}

Nogovitsyn D.D., Sheina Z.M., Sergeeva L.P.

The V.P. Larionov Institute of Physical and Technical Problems of the North, Siberian Branch of the Russian Academy of Science (IPTPN SB RAS), Yakutsk, e-mail: dmitry.nogovitzyn@yandex.ru

The most important component of wind energy development is the determination of its resource potential. Characteristics of the wind resource in the Far North with its vast territory and harsh long winter are of great importance for all aspects of using wind energy, ranging from choosing a suitable location for wind farms to determining the types of wind power plants that are suitable for these conditions. In Yakutia, Arctic zone have the greatest wind energy potential. In this regard, the calculation of wind energy reserves in the Arctic territory of Yakutia is of practical importance for areas remote from sources of centralized power supply, and for relatively small energy consumers dispersed over large areas. Currently, in connection with the rising cost of imported liquid and solid fuels to remote isolated areas of the republic, it becomes urgent to explore the possibilities of using local renewable energy sources associated with saving fuel and energy resources and solving environmental problems. The main attention is paid to the definition of wind energy potential in the territory of Yakutia. The need to clarify the reserves of wind energy is due to the direct dependence of the wind regime on the surrounding relief and the geographical location of the observation point. Analysis of average annual wind speeds on weatherstations showed that the strongest winds are observed on the coast of the Arctic Ocean (Anabarsky, Bulunsky, Ust-Yansky, Allaikhovsky and Nizhnekolymsky districts) and the lower course of the Lena River. Wind energy characteristics throughout the Republic of Sakha (Yakutia) have been calculated. Since, wind energy is a priority for pre-selected areas, additional research is needed to clarify the values of wind speeds, their frequency and direction in order to accurately estimate the wind energy potential and substantiate the placement of wind power plants.

Keywords: Yakutia, Arctic, wind energy resources, wind speed, wind energy potential

В настоящее время электро- и теплоснабжение поселков, расположенных в удаленных районах Якутии, требует специфического подхода. Это определяется разбросанностью потребителей по территории Крайнего Севера, отсутствием централизованного электроснабжения этих районов, высокой стоимостью органического топлива с учетом его перевозки, большой продолжительностью отопительного сезона и низкими температурами наружного воздуха. Обеспечение устойчивого электроснабжения населения в удаленных улусах республики требует проведения ресурсных, технико-экономических, экологических исследований возобновляемой энергетики. Возобновляемые источники энергии в основном используются в отдаленных и труднодоступных районах отдаленного Дальнего Востока [1-3]. Из всего многообразия 
возобновляемых источников энергии в арктических районах Якутии приоритетной является энергия ветра. В условиях Якутии наиболее рационально сочетать работу ветроустановок с дизельными электростанциями и малыми ГЭС и при совместной работе получить экономию жидкого топлива Продолжительность энергоиспользуемых ветров, дующих со скоростью 4 м/с и выше, составляет от 150 до 280 дней в году.

Цель исследования: На основе составления кадастра ветровой энергии выявить возможности их использования для энергоснабжения в арктической зоне Якутии.

Метод исследования: использование методов расчета ветровой энергии [4].

Природные условия. Якутия - страна гор, плоскогорий, низменностей. Здесь расположены обширные горные системы хребты Верхоянский, Черского, связанные между собой Яно-Оймяконским плоскогорьем, Сетте-Дабан, Юдомо-Майское нагорье, Становой хребет, высоты которых колеблются от 2000 до 2412 м. На севере и в центре расположены такие низменности, как Яно-Индигирская, Колымская и Центрально-Якутская.

Вся территория республики лежит в зоне вечной мерзлоты. Климат суровый, резко континентальный. Годовая температура воздуха составляет более $100^{\circ}$.

Ветровой режим. Ветер, формирующийся под воздействием центров давления, характеризуется изменением противоположных направлений ветра и скоростей от 0,9-4,5 м/с внутри территории до 3,56,8 м/с на островах и побережьях морей Лаптевых и Восточно-Сибирского [5]. На большей части территории наибольшую повторяемость имеют ветры слабые и умеренные скорости ветра от 0 до $5 \mathrm{~m} / \mathrm{c}$ (около $93 \%$ ). Наибольшее количество малых скоростей ветра (до 2 м/с) наблюдается зимой, умеренных скоростей (до 5 м/с) - летом. На островах морей Лаптевых и Восточно-Сибирского наибольший процент приходится на ветры со скоростью 4-5 м/с, а на о. Четырехстолбовом -6-7 м/с [5].

На направление и скорость ветра влияют также физико-географические особенности исследуемой местности [3].

Зимой ветровой режим зависит от господствующего в это время отрога зимнего азиатского антициклона. Такой ветровой режим сохраняется с сентября по март .

Летом на побережьях морей Лаптевых и Восточно-Сибирского ветры имеют муссонный характер. На большей части терри- тории Якутии дуют северные, северо-восточные, северо-западные, западные ветры и южные ветры. Направления ветров остаются летними с мая по август [5].

В сентябре и апреле зимнее распределение ветра сочетается с летним.

\section{Результаты исследования и их обсуждение}

В последние десятилетия климат в Арктике однозначно изменился [6]. По данным Межправительственной группы экспертов изменение ветрового режима может быть следствием изменения траектории перемещения циклонов умеренных широт, их интенсивности и частоты, общего усиления циклонов в Арктике [7].

Согласно прогнозу [8], к концу XXI в. средняя годовая скорость ветра в Арктике над континентальной частью Якутии практически не изменится, над морями вдоль побережья знак аномалии в основном положительный. Рост значений ветра наиболее выражен в осенне-зимний период.

Анализ среднегодовых скоростей ветра метеостанций Якутии показал, что скорость более $3 \mathrm{~m} / \mathrm{c}$ превалирует в северной части республики. Наилучшим для использования на цели энергоснабжения является внутригодовое распределение ветропотенциала, имеющее зимний максимум, поскольку в большей степени соответствует графику нагрузки потребителей, изолированных от энергосистем [9].

Метеорологические факторы являются определяющими для ветроэнергетики. От метеорологических условий в том или ином выбранном месте зависит решение о целесообразности применения ветродвигателей в намеченном месте, определение их оптимальных параметров и планирование режима работы, оценка выдаваемой ими энергии, планирование мер по защите их от воздействия вредных метеорологических явлений. При этом основную роль играет климатическая информация, характеризующая средние многолетние условия.

В работе оценка ветроэнергоресурсов проведена непосредственно по данным справочника [5]. Оценка потенциала ветровой энергии по числу случаев по градациям скоростей выполнена методами $[4,10]$. Для увеличения точности вычислений и сглаживания полученной функции на основе этих методов [4, 10] выполнена линейная интерполяция (метод частот) и интерполяция кубическими сплайнами. 
Таблица 1

Потенциал ветровой энергии, рассчитанный различными методами

\begin{tabular}{|l|c|c|c|c|}
\hline \multirow{2}{*}{$\begin{array}{c}\text { Название } \\
\text { пункта }\end{array}$} & Длина ряда & \multirow{2}{*}{$\begin{array}{l}\text { Метод } \\
\text { частот }\end{array}$} & & \multicolumn{2}{c|}{ Потенциал, вт/кв.м } \\
\cline { 4 - 5 } & & & $\begin{array}{c}\text { Расчеты с учетом } \\
\text { плотности воздуха }\end{array}$ & $\begin{array}{c}\text { Метод кубических } \\
\text { сплайнов }\end{array}$ \\
\hline Кигилях, мыс & 13 & 222,7 & 209 & 212,8 \\
\hline Тикси, бухта & 13 & 341,3 & 334 & 329,3 \\
\hline Нижнеянск & 13 & 112,3 & 106 & 104,8 \\
\hline Найба & 10 & 98,7 & 92 & 93,2 \\
\hline Юбилейная & 12 & 69,6 & 67 & 63,7 \\
\hline Кулар & 12 & 208,5 & 191 & 43,3 \\
\hline Куйга & 11 & 47,6 & 46 & 26,0 \\
\hline Джангкы & 10 & 29,0 & 27 & 13,8 \\
\hline Намы & 10 & 16,3 & 15 & 35,7 \\
\hline Депутатский & 13 & 39,8 & 39 & 15,7 \\
\hline Янск & 9 & 19,0 & 18 & \\
\hline
\end{tabular}

Средние абсолютная и относительная погрешности результатов

Таблица 2 в зависимости от средней скорости

\begin{tabular}{|c|c|c|}
\hline $\begin{array}{c}\text { Средняя } \\
\text { скорость }\end{array}$ & $\begin{array}{c}\text { Средняя абсолютная } \\
\text { погрешность, т/кв.м }\end{array}$ & $\begin{array}{c}\text { Средняя относительная } \\
\text { погрешность, } \%\end{array}$ \\
\hline $0-1,0$ & 1,16 & 22,4 \\
\hline $1,0-1,5$ & 1,85 & 17,7 \\
\hline $1,5-2,0$ & 2,71 & 15,6 \\
\hline $2,0-2,5$ & 3,81 & 11,8 \\
\hline $2,5-3,0$ & 4,64 & 8,56 \\
\hline $3,0-3,5$ & 5,83 & 8,13 \\
\hline $3,5-4,0$ & 6,58 & 6,54 \\
\hline $4,0-4,5$ & 8,16 & 5,17 \\
\hline $4,5-5,0$ & 10,17 & 4,38 \\
\hline $5,0-5,5$ & 9,98 & 4,21 \\
\hline $5,5-6,0$ & 10,89 & 4,02 \\
\hline
\end{tabular}

Сравнительный анализ результатов расчета энергии ветра показал, что наиболее предпочтительной является методика, позволяющая использовать интерполяцию кубическими сплайнами (табл. 1).

В тех случаях, когда средняя скорость ветра меньше 2,5 м/с, ни один метод не может дать достоверных результатов, так как почти вся выборка попадает в один или два промежутка и выявить закономерности затруднительно (табл. 2).

Для практики интерес представляют методы, дающие достоверный результат расчета потенциала ветровой энергии, при средних скоростях ветра, когда эксплуатация ветроагрегата экономически целесообразна. Как правило, случаи, когда средняя скорость ветра меньше 2,5 м/с, народнохозяйственного значения не имеют.

В табл. 3 приводятся данные по повторяемости ветров по градациям скоростей ветра. Наиболее благоприятные условия для работы ветроэнергетических установок имеют п. Андрюшкино, Чокурдах, Жиганск, Нижнеянск и Тикси. В этих пунктах повторяемость ветров со скоростью более 4 м/с очень высока.

Наиболее сильные ветра, скорость которых составляет более $3 \mathrm{~m} / \mathrm{c}$ наблюдаются на побережье Северного Ледовитого океана (Аллаиховский, Анабарский, Булунский, Усть-Янский и Нижнеколымский районы) и нижнего течения р. Лена (Жиганский) (табл. 4). 
Таблица 3

Повторяемость ветров по градациям скоростей по некоторым пунктам РС(Я)

\begin{tabular}{|l|c|c|c|c|c|c|}
\hline \multicolumn{1}{|c|}{ Пункты } & 4 & 6 & 8 & 10 & 12 & 14 и более \\
\hline Андрюшкино & 3165 & 1447 & 509 & 148 & 25 & 4 \\
\hline Батамай & 1570 & 531 & 146 & 41 & 11 & 3 \\
\hline Верхоянск & 547 & 147 & 33 & 10 & 3 & 1 \\
\hline Депутатский & 1745 & 492 & 139 & 50 & 21 & 5 \\
\hline Жиганск & 3977 & 1898 & 1028 & 485 & 211 & 99 \\
\hline Куйга & 1964 & 710 & 212 & 55 & 17 & 6 \\
\hline Кюсюр & 3253 & 1920 & 935 & 389 & 126 & 37 \\
\hline Нижнеянск & 3954 & 1709 & 669 & 238 & 72 & 19 \\
\hline Оленек & 1910 & 549 & 145 & 33 & 6 & 2 \\
\hline Саскылах & 2987 & 1258 & 512 & 215 & 98 & 44 \\
\hline Тикси & 3995 & 2562 & 1556 & 952 & 613 & 373 \\
\hline Чокурдах & 4031 & 1614 & 620 & 199 & 76 & 25 \\
\hline Эйк & 1480 & 383 & 104 & 37 & 3 & 1 \\
\hline
\end{tabular}

Таблица 4

Ветроэнергетические характеристики на территории Республики Саха (Якутия)

\begin{tabular}{|c|c|c|c|c|}
\hline $\begin{array}{l}\text { № } \\
\text { N/ா }\end{array}$ & Районы & $\begin{array}{c}\text { Средняя скорость } \\
\text { ветра, м/с } \\
\end{array}$ & $\begin{array}{c}\text { Удельная мощность, } \\
\mathrm{BT} / \mathrm{M}^{2} \\
\end{array}$ & $\begin{array}{c}\text { Выработка электроэнер- } \\
\text { гии, тыс. кВт·ч/м² }\end{array}$ \\
\hline 1 & Алданский & $0,9-2,7$ & $3-50$ & $45-450$ \\
\hline 2 & Таттинский & 1,3 & 10 & 87 \\
\hline 3 & Аллаиховский & 4,1 & 100 & 890 \\
\hline 4 & Амгинский & $1,3-1,7$ & $12-17$ & $110-150$ \\
\hline 5 & Анабарский & $3,3-5,6$ & $90-222$ & $800-1900$ \\
\hline 6 & Булунский & $1,6-6,5$ & $14-480$ & $120-4200$ \\
\hline 7 & Верхневилюйский & 2,3 & 26 & 230 \\
\hline 8 & Верхнеколымский & 2,3 & $30-35$ & $270-300$ \\
\hline 9 & Верхоянский & $1,2-2,6$ & $10-42$ & $90-370$ \\
\hline 10 & Вилюйский & 1,8 & 14 & 123 \\
\hline 11 & Горный & $1,4-2,6$ & $10-53$ & $96-470$ \\
\hline 12 & Жиганский & $2,4-4,3$ & $34-150$ & $300-1300$ \\
\hline 13 & Кобяйский & $2,4-3,4$ & $34-107$ & $300-930$ \\
\hline 14 & Нюрбинский & 2,4 & $26-30$ & $230-260$ \\
\hline 15 & Ленский & $1,2-2,5$ & $6-32$ & $60-280$ \\
\hline 16 & Мирнинский & $1,1-3,5$ & $6-60$ & $50-550$ \\
\hline 17 & Намский & 2,1 & 21 & 180 \\
\hline 18 & Нижнеколымский & $3,1-4,8$ & $49-147$ & $430-1300$ \\
\hline 19 & Оймяконский & $0,9-2,7$ & $3-64$ & $25-560$ \\
\hline 20 & Олекминский & $0,9-2,4$ & $3-28$ & $28-250$ \\
\hline 21 & Оленекский & $1,6-2,6$ & $17-37$ & $150-320$ \\
\hline 22 & Хангаласский & $1,0-2,4$ & $6-42$ & $53-360$ \\
\hline 23 & Среднеколымский & 1,8 & 12 & 103 \\
\hline 24 & Сунтарский & $1,3-2,2$ & $7-22$ & $64-190$ \\
\hline 25 & Томпонский & $0,8-2,2$ & $3-18$ & $22-160$ \\
\hline 26 & Усть-Алданский & $1,3-2,6$ & $11-36$ & $96-310$ \\
\hline 27 & Усть-Майский & $1,1-1,5$ & $6-12$ & $61-105$ \\
\hline 28 & Усть-Янский & $1,8-5,2$ & $26-310$ & $23-2750$ \\
\hline 29 & Чурапчинский & 1,6 & 12 & 107 \\
\hline 30 & г. Якутск & 1,8 & 14 & 120 \\
\hline 31 & Нерюнгринский & $0,9-2,9$ & $5-84$ & $41-730$ \\
\hline
\end{tabular}




\section{Выводы}

1. Анализ среднегодовых скоростей ветра метеостанций Якутии показал, что скорость более $3 \mathrm{~m} / \mathrm{c}$ превалирует в северной части республики. Наилучшим для использования на цели энергоснабжения является внутригодовое распределение ветропотенциала, имеющее зимний максимум, поскольку в большей степени соответствует графику нагрузки потребителей, изолированных от энергосистем.

2. Наиболее благоприятные условия для работы ветроэнергетических установок имеют п. Андрюшкино, Чокурдах, Жиганск, Нижнеянск и Тикси. Поскольку для выбранных районов энергия ветра является приоритетной, необходимы дополнительные научно-исследовательские работы по уточнению значений скоростей ветров, их повторяемости и направлению для точной оценки ветроэнергетического потенциала и обоснования размещения ветроэлектростанций.

\section{Список литературы / References}

1. Санеев Б.Г., Иванова И.Ю., Тугузова Т.Ф. Проблемы энергетики восточной зоны Российской Арктики и возможные пути решения // Энергетическая политика. 2018. № 4. C. 80-88.

Saneev B.G., Ivanova I.Yu., Tuguzova T.F. Energy problems of the Eastern zone of the Russian Arctic and possible solutions // Energy policy. 2018. № 4. P. 80-88 (in Russian).

2. Санеев Б.Г., Иванова И.Ю., Тугузова Т.Ф. Развитие возобновляемой энергетики на востоке РФ в первой половине XXI века на фоне общероссийских тенденций // Энергетическая политика. 2016. № 3. С. 66-73.

Saneev B.G., Ivanova I.Yu., Tuguzova T.F. Development of renewable energy in the East of the Russian Federation in the first half of the XXI century against the background of all-Russian trends // Energy policy. 2016. № 3. P. 66-73 (in Russian).

3. Иванова И.Ю., Ноговицын Д.Д., Тугузова Т.Ф., Шеина 3.М., Сергеева Л.П. Ветроэнергетические ресурсы г. Верхоянска Республики Саха (Якутия) и возможность их использования для энергоснабжения // Фундаментальные исследования. 2013. № 4 (1) С. 30-38.
Ivanova I.Yu., Nogovitsyn D.D., Tuguzova T.F., Shakirov V.A., Sheina Z.M., Sergeeva L.P. Wind energy resources of the city of Verkhoyansk Sakha Republic (Yakutia) and the possibility of their use for energy supply // Fundamental Research. 2013. № 4 (1). P. 30-38 (in Russian).

4. Калиткин Н.Н. Численные методы. М.: Наука, 1978. $512 \mathrm{c}$

Kalitkin N.N. Numerical method. M.: Nauka, 1978. 512 p. (in Russian).

5. Справочник по климату СССР. Вып. 24. Якутская ACСР. Ч. 3. Ветер. Л.: Гидрометеоиздат, 1967. 271 с.

The USSR Climate Handbook. Issue 24. Yakut ASSR. Part 3. Wind. L.: Hydrometeoizdat, 1967. 271 p. (in Russian).

6. Dee D.P., Uppala S.M., Simmons A.J., Berrisford P., Poli P., Kobayashi S., Andrae U., Balmaseda M.A., Baisamo G., Bauer P., Bechtold P., Beljaars ACM, van de Berg L., Bidlot J., Bormann N., Delsol C., Dra-gani R., Fuentes M., Geer A.J., Yfimberger L., Healy S.B., Hersbach H., H’olm E.V., Isaksen L., $\mathrm{K}^{\circ}$ allberg P., K'ohier M., Matricardi M., McNally A.P., MongeSanz B.M., Morcrette J.-J., Park B.-K., Peubey C., de Rosnay P., Tavolato C., Th epaut J.-N., Vitart F. The ERA-Interim reanalysis: configuration and per-formance of the data assimilation system. Q.J.R. Meteorol.Soc. 2011. V. 137. P. 553-597. DOI: $10.1002 /$ qj.828.

7. IPCC (2013). Climate Change 2013: The Physical Science Basis. Contribution of Working Group I to the Fifth Assessment Report of the Intergovernmental Panel on Climate Change / Edited by T.F. Stocker, D. Qin, G-K. Plattner, M. Tignor, S.K. Fllen, J. Boschung, A. Nauels, Y. Xia, V. Bex and P.M. Midgley. Cambridge University Press. Cambridge, United Kinddom and New York, USA. 2013. 1535 p.

8. Суркова Г.В., Крылов А.А. Изменения средних и экстремальных скоростей ветра в Арктике в конце XXI века // Арктика и Антарктика. 2018. № 3. С. 26-36. DOI: $10.7256 / 2453-8922.2018 .3 .27395$.

Surkova G.V., Krylov A.A. Changes in average and extreme wind speeds in the Arctic at the end of the 21 st century // Arctic and Antarctic. 2018. № 3. Р. 26-36 (in Russian).

9. Иванова И.Ю., Ноговицын Д.Д., Тугузова Т.Ф., Шакиров В.А., Шеина 3.М., Сергеева Л.П. Факторы, влияющие на эффективность использования ветропотенциала в локальной энергетике Якутии // Известия РАН. Энергетика. 2017. № 1. C. 84-92.

Ivanova I.Yu., Nogovitsyn D.D., Tuguzova T.F., Shakirov V.A., Sheina Z.M., Sergeeva L.P. Factors affecting the efficiency of wind potential in the local energy of Yakutia // Proceedings of the Russian Academy of Sciences. Power Engineering. 2017. № 1. P. 84-92 (in Russian).

10. Марчук Г.И. Численные методы расчета ядерных реакторов. М.: Атомиздат, 1958. 382 с.

Marchuk G.I. Numerical methods for calculating nuclear reactors. M.: Atomizdat, 1958. 382 p. (in Russian). 